\title{
NGUYÊN NHÂN TỬ VONG THEO NHÓM TUỎI TẠI TỈNH ĐIỆN BIÊN NĂM 2017
}

\author{
Hoàng Thị Hải Vân và Nguyễn Phương Hoa², \\ ${ }^{1}$ Viện Đào tạo YHDP và YTCC, Trường Đại học Y Hà Nội \\ ${ }^{2}$ Trường Đại học Y Hà Nội
}

Nguyên nhân tử vong ở các lứa tuổi khác nhau đóng vai trò quan trọng trong việc định hướng các nghiên cứu cũng như việc lập kế hoạch và định hướng các hoạt động y tế từ phạm vi địa phương, đến quốc gia cũng như thế giới. Kết quả nghiên cứu nguyên nhân tử vong tại Điện Biên năm 2017 cho thấy nguyên nhân tử vong tại Điện Biên khác nhau giữa các lứa tuổi: lứa tuổi trẻ từ 1 tới dưới 5 tuổi, nguyên nhân gây tử vong hàng đầu vẫn là nguyên nhân viêm phổi với tỉ lệ 41,3\%; nhóm tuổi 5 - 14 tuổi, nguyên nhân do đuối nước đứng đầu trong các nguyên nhân gây tử vong với 22,2\%; đặc biệt nguyên nhân hàng đầu gây tử vong ở nhóm tuổi 15 - 49 là bệnh HIVIAIDS với tỉ lệ 9,6\%; nhóm tuổi 50 - 59 tuổi, nguyên nhân gây tử vong hàng đầu là tai biến mạch máu não với 19,8\%; nguyên nhân hàng đầu gây tử vong ở người cao tuổi là bệnh tai biến mạch máu não chiếm 23,9\%. Đáng chú ý tỷ lệ tử vong tại nhà chiếm 77,9\%. Đây là một khó khăn cho công tác thống kê tử vong và nguyên nhân tử vong khi người bệnh xin về khi không còn hy vọng sống sót hoặc không còn khả năng kinh tế để theo đuổi việc điều trị.

Từ khóa: tử vong theo tuổi, nguyên nhân, Điện Biên, Việt Nam.

\section{I. ĐẠT VẤN ĐỀ}

Thông tin về mô hình tử vong là một trong những yếu tố quan trọng giúp cho việc lập kế hoạch và hoạch định chính sách y tế. Các số liệu về tử vong là một trong những chỉ số y tế quan trọng cung cấp bằng chứng để đo lường tình trạng sức khỏe của các quốc gia. Thông tin về nguyên nhân tử vong sẽ giúp cho việc đánh giá gánh nặng bệnh tật ở những địa bàn khác nhau. Việc tìm hiểu mô hình tử vong được coi là một yếu tố quan trọng trong định hướng các hoạt động y tế và hỗ trợ việc xây dựng chính sách dựa trên bằng chứng. Mặt khác, tử vong là một chỉ số dễ đo lường hơn so với những chỉ số y tế khác như số liệu về tình hình mắc bệnh. Người ta cũng thường giả định rằng sự thay

Tác giả liên hệ: Nguyễn Phương Hoa

Trường Đại học Y Hà Nội

Email: nguyenphuonghoa@hmu.edu.vn

Ngày nhận: 01/04/2021

Ngày được chấp nhận: 19/07/2021 đổi về mô hình tử vong phản ánh phần nào bức tranh của mô hình bệnh tật. ${ }^{1-3}$

Tầm quan trọng của các chỉ số đo lường mô hình tử vong còn được thể hiện trong hai mục tiêu thiên niên kỷ và là một trong 3 yếu tố cấu thành nên chỉ số phát triển con người (Human Development Index) của Liên hợp quốc. ${ }^{4}$ Năm 2006, Tổ chức $Y$ tế thế giới (WHO) đã nhấn mạnh đến tầm quan trọng của thông tin tử vong bằng việc xuất bản chuyên san đặc biệt về hệ thống giám sát tử vong trong đó nhấn mạnh tầm quan trọng của tử vong trong đo lường tình hình sức khỏe của người dân ở cộng đồng, WHO cũng đã khẳng định "đo lường tử vong là rất cần thiết đối với ngành y tế”. Tài liệu này cũng nêu rõ cần phải có nhiều nỗ lực hơn nữa trong việc thu thập số liệu sao cho những số liệu đó đảm bảo sự chính xác để phục vụ việc hoạch định chính sáchchăm sóc sức khỏe. ${ }^{1}$

Mặc dù vậy, hiện nay nhiều quốc gia vẫn chưa có được hệ thống thu thập và đăng ký 
số liệu tốt và đáng tin cậy. Trong báo cáo đánh giá về thực trạng số liệu tử vong của 115 nước thành viên của $\mathrm{WHO}$, chỉ có 64 quốc gia có được những số liệu đáng tin cậy về nguyên nhân tử vong theo tuổi và giới. ${ }^{1}$ Cũng theo đánh giá này, hệ thống đăng ký tử vong chỉ ghi nhận được $10 \%$ ở khu vực Châu Phi và khu vực châu Á Thái Bình Dương. Chính vì vậy, WHO đã khuyến cáo về sự cần thiết cho các quốc gia phải thu thập thông tin về tử vong, thậm chí ban đầu có thể chỉ trong phạm vi giới hạn như tại các cơ sở thực địa dịch tễ học để có thể hiểu biết về nguyên nhân tử vong. ${ }^{5,6}$

Ở Việt Nam, số liệu từ các cơ sở y tế là nguồn cung cấp chính cho Niên giám thống kê y tế được Bộ $Y$ tế xuất bản hàng năm. Những số liệu thu thập từ cộng đồng đang còn rất thiếu, mặt khác, hầu hết các trường hợp tử vong xảy ra tại nhà sẽ không được báo cáo với nhân viên y tế và cơ quan y tế, chính vì thế không thể cung cấp đầy đủ các bằng chứng cho việc lập kế hoạch và hoạch định chính sách y tế. ${ }^{7}$

Hiện nay, Việt Nam đang trong quá trình chuyển đổi dịch tễ học, mô hình bệnh tật và tử vong đã có những thay đổi, với sự gia tăng của nhóm các bệnh không lây nhiễm và tai nạn thương tích, bên cạnh đó một số bệnh thuộc nhóm lây nhiễm vẫn chưa được khống chế như HIVIAIDS và bệnh lao. ${ }^{8}$ Vì vậy chúng tôi tiến hành nghiên cứu đề tài này nhằm mục tiêu: Mô tả nguyên nhân tử vong ở các lứra tuổi khác nhau tại tỉnh Điện Biên năm 2017.

\section{II. ĐỐ TƯƠ'NG VÀ PHƯƠNG PHÁP}

\section{1. Đối tượng}

\section{Địa điểm nghiên cứu}

Nghiên cứu được thực hiện tại 100 xã thuộc tỉnh Điện Biên. Đây là những xã có bác sĩ, đã được tập huấn ghi chép sổ A6.

\section{Đối tượng và thời gian nghiên cứu}

Nghiên cứu được tiến hành đối với tất cả các trường hợp tử vong từ 01/01/2017 đến 31/12/2017 với mọi lứa tuổi tại 100 xã trong tổng số 130 đơn vị cấp xã thuộc tỉnh Điện Biên (9 phường, 5 thị trấn và 116 xã). Đây là 100 xã đã được tập huấn và hướng dẫn ghi chép sổ A6 theo nguyên nhân trong khi các xã khác chỉ thống kê là tử vong do già hoặc do bệnh. Mặt khác việc ghi chép sổ $A 6$ tại 100 xã này do các bác sĩ tiến hành, trong khi các xã khác do y sĩ thực hiện. Tổng số trường hợp tử vong thuộc địa bàn của 100 xã ở tỉnh Điện Biên ghi nhận được trong điều tra này là 2856 trường hợp.

Thông tin của tất cả các trường hợp tử vong thuộc địa bàn xã được ghi nhận trong sổ ghi chép tử vong (A6/YTCS) của trạm y tế xã, (thực hiện theo thông tư số 27/2014/TT-BYT, năm 2014). ${ }^{9}$

\section{Thời gian thu thập số liệu}

Thu thập số liệu từ tháng 4 - 9/2019.

\section{Thiết kế nghiên cứu}

Nghiên cứu mô tả cắt ngang.

\section{Xử lý số liệu}

Số liệu được nhập và quản lý bằng phần mềm Epidata 3.1, trực tiếp từ số liệu được ghi chép trên sổ A6 của các xã bao gồm các biến số: ngày tháng vào sổ, tuổi, giới, địa chỉ, dân tộc, ngày tháng tử vong, nguyên nhân tử vong.

Số liệu được phân tích bằng phần mềm Stata 15.0. Test khi bình phương $\left(X^{2}\right)$ được sử dụng để so sánh sự khác biệt giữa các nhóm. Mức có ý nghĩa thống kê là $p<0,05$. Nguyên nhân tử vong được phân tích theo các nhóm bệnh dựa vào phân loại quốc tế bệnh tật ICD-10.

\section{3. Đạo đức nghiên cứu}

Nghiên cứu này chỉ sử dụng phương pháp thu thập số liệu đã được ghi nhận sã̃n ở sổ ghi chép tử vong A6/YTCS, của hệ thống y tế đã được sự cho phép của lãnh đạo Sở $Y$ tế tỉnh Điện Biên. Kết quả nghiên cứu chỉ phục vụ công tác nghiên cứu khoa học và xây dựng kế hoạch chăm sóc sức khỏe của địa phương. 


\section{KẾT QUẢ}

Bảng 1. Một số đặc điểm của các trường hợp tử vong tại tỉnh Điện Biên

\begin{tabular}{cccc}
\hline & Đặc điểm chung & Số lượng & Tỷ lệ (\%) \\
\cline { 2 - 4 } & $0-14$ tuổi & 670 & 23,4 \\
\cline { 2 - 4 } Nhóm tuổi & $15-49$ tuổi & 710 & 24,9 \\
\cline { 2 - 4 } & $50-59$ tuổi & 288 & 10,1 \\
\cline { 2 - 4 } & $\geq 60$ tuổi & 1188 & 41,6 \\
\hline \multirow{2}{*}{ Giới tính } & Nam & 1786 & 62,5 \\
\cline { 2 - 4 } Nghề nghiệp & Nữ & 1070 & 37,5 \\
\cline { 2 - 4 } & Làm ruộng & 1964 & 68,8 \\
\hline \multirow{2}{*}{ Địa điểm tử vong } & Khác & 892 & 31,2 \\
\cline { 2 - 4 } & Tại nhà & 2225 & 77,9 \\
\cline { 2 - 4 } & Tại cơ sở y tế & 434 & 15,2 \\
\hline & Nơi khác & 197 & 6,9 \\
\hline
\end{tabular}

Trong tổng số 2856 trường hợp tử vong trong cả năm 2017 được ghi nhận tại Điện Biên, 1789 đối tượng là nam chiếm 62,64\%, nữ giới có 1067 trường hợp chiếm 37,36\%.

Số trường hợp tử vong có nghề là làm ruộng là 1964 trường hợp chiếm 68,8\%, các trường hợp tử vong ở các nhóm nghề khác là 892 trường hợp chiếm 31,2\%.

Đa số các trường hợp là tử vong tại nhà chiếm tỉ lệ 77,9\%, số trường hợp tử vong tại cơ sở y tế chỉ là $15,2 \%$.

Bảng 2. Một số nguyên nhân tử vong thường gặp theo giới

\begin{tabular}{cccccc}
\hline \multirow{2}{*}{ Nguyên nhân } & \multicolumn{2}{c}{ Nam } & \multicolumn{2}{c}{ Nũ } & p \\
\cline { 2 - 6 } & $\mathbf{n}$ & $\%$ & $\mathbf{n}$ & $\%$ & \\
\hline Viêm phổi & 258 & 14,4 & 208 & 19,5 & 0,000 \\
\hline Tai biến mạch máu não & 258 & 14,4 & 156 & 14,6 & 0,884 \\
\hline Tâm phế mạn & 94 & 5,3 & 95 & 8,9 & 0,000 \\
\hline Xơ gan & 70 & 3,9 & 18 & 1,7 & 0,001 \\
\hline Ung thư phổi & 64 & 3,6 & 19 & 1,8 & 0,006 \\
\hline HIV/AIDS & 65 & 3,6 & 17 & 1,6 & 0,002 \\
\hline Suy tim & 37 & 2,1 & 43 & 4,0 & 0,002 \\
\hline Ung thư gan & 64 & 3,6 & 15 & 1,4 & 0,001 \\
\hline Hen phế quản & 38 & 2,1 & 23 & 2,2 & 0,955 \\
\hline
\end{tabular}




\begin{tabular}{cccccc}
\hline Tai nạn giao thông & 45 & 2,5 & 12 & 1,1 & 0,010 \\
\hline Các nguyên nhân khác & 763 & 42,6 & 450 & 42,2 & 0,804 \\
\hline Không xác định được nguyên nhân & 33 & 1,8 & 11 & 1,0 & 0,088 \\
\hline Tổng & 1789 & 100,0 & 1067 & 100,0 & \\
\hline
\end{tabular}

Xem xét các trường hợp tử vong theo giới cho thấy tỉ lệ viêm phổi ở nữ giới cao hơn ở nam giới (19,5\% so với $14,4 \%, p<0,05)$, tỉ lệ tâm phế mạn ở nữ cũng cao hơn ở nam (8,9\% so với $5,3 \%$, p $<0,05)$. Tỉ lệ tai biến mạch máu não ở nam và nữ là tương đương nhau, sự khác biệt này chưa có giá trị thống kê $(14,4 \%$ so với $14,6 \%, p>0,05)$.

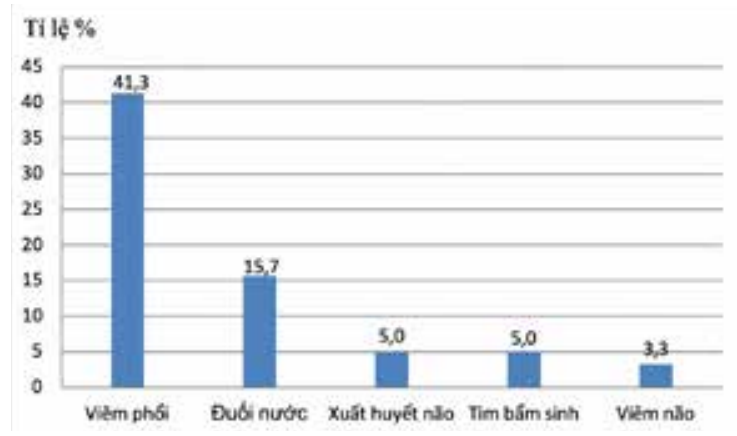

Biểu đồ 1. Nguyên nhân gây tử vong thường gặp ở trẻ 1 - < 5 tuổi

Ở nhóm tuổi trẻ từ 1 tới dưới 5 tuổi, nguyên nhân gây tử vong hàng đầu vẫn là nguyên nhân viêm phổi với tỉ lệ 41,3\%. Xếp thứ hai là nguyên nhân do đuối nước với tỉ lệ 15,7\%. Tiếp theo là bệnh do dị dạng mạch não và tim bẩm sinh, đều chiếm tỉ lệ 5,0\%.

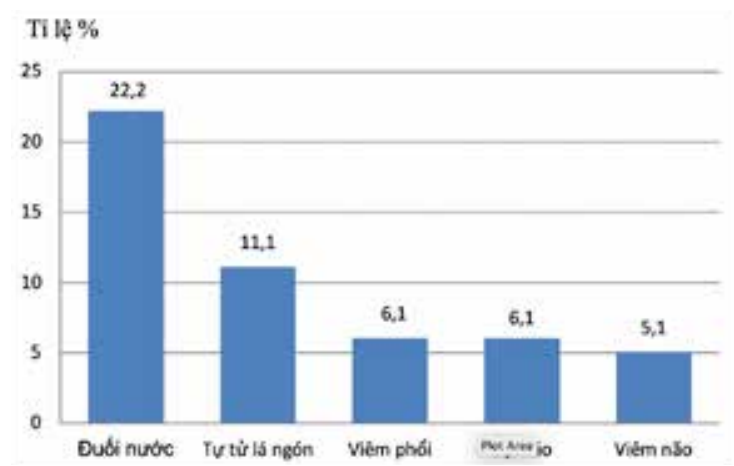

Biểu đồ 2. Nguyên nhân gây tử vong thường gặp ở nhóm tuổi 5 - 14

Ở nhóm tuổi 5 - 14 tuổi, nguyên nhân tử vong hàng đầu là đuối nước chiếm 22,2\%; nguyên nhân đứng thứ hai gây tử vong ở lứa tuổi này là tự tử bằng lá ngón với tỉ lệ 11,1\%. Nguyên nhân viêm phổi đứng trong tốp các nguyên nhân gây tử vong thường gặp, với tỉ lệ 6,1\%.

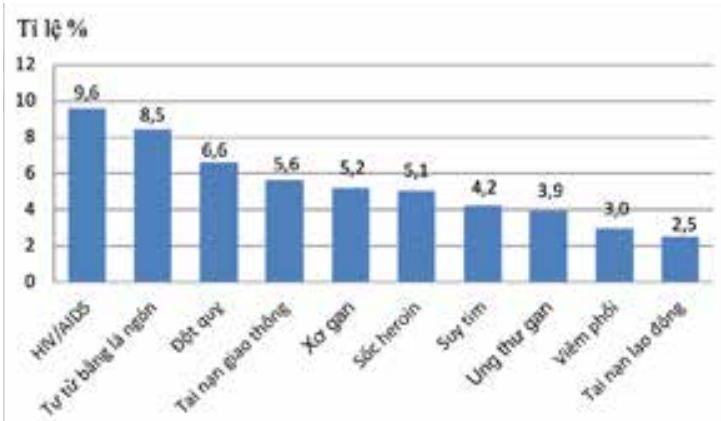

Biểu đồ 3. Nguyên nhân gây tử vong thường gặp ở nhóm tuổi 15 - 49

Nguyên nhân hàng đầu gây tử vong ở nhóm tuổi 15 - 49 là bệnh HIVIAIDS với tỉ lệ 9,6\%. Tiếp theo là nguyên nhân do tự tử bằng lá ngón vẫn đứng tốp cao với tỉ lệ $8,5 \%$. Xếp thứ 3 là nguyên nhân do đột quỵ với tỉ lệ 6,6\%.

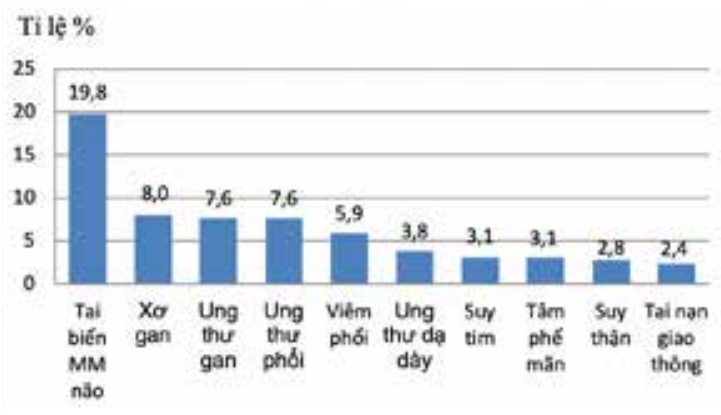

\section{Biểu đồ 4. Nguyên nhân gây tử vong thường gặp ở nhóm tuổi 50 - 59}

Ở nhóm tuổi 50 - 59 tuổi, nguyên nhân gây tử vong hàng đầu là tai biến mạch máu não với $19,8 \%$. Tiếp theo là nguyên nhân do xơ gan với $8,0 \%$. Xếp thứ ba là các bệnh lý ung thư gan và ung thư phổi đều chiếm $7,6 \%$. 


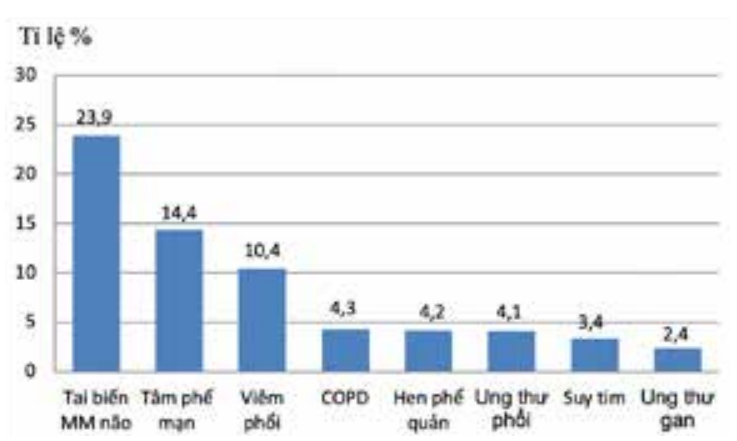

\section{Biểu đồ 5. Nguyên nhân gây tử vong thường gặp ở nhóm tuổi 60 +}

Nguyên nhân hàng đầu gây tử vong ở người cao tuổi là bệnh tai biến mạch máu não chiếm 23,9\%. Tiếp theo là nguyên nhân do tâm phế mạn $14,4 \%$. Bệnh viêm phổi cũng chiếm tỷ lệ khá cao với $10,4 \%$ xếp thứ ba.

\section{BÀN LUẬN}

Đa số trường hợp tử vong xảy ra tại nhà $77,9 \%$, chỉ có $15,2 \%$ các trường hợp tử vong tại các cơ sở y tế, vì vậy nếu chỉ phân tích những số liệu tử vong từ các cơ sở y tế thì không đủ và không đại diện được cho mô hình tử vong ở cộng đồng. Kết quả này cho thấy, việc thống kê số liệu tử vong và nguyên nhân tử vong gặp rất nhiều khó khăn và khó có thể có con số chính xác đặc biệt là các số liệu thống kê tử vong theo nguyên nhân. Việc mong muốn xin về tử vong tại nhà vốn là văn hoá của người Việt Nam, khi đó người bệnh được thống kê ở bệnh viện là gia đình xin về tuy nhiên tình trạng của người bệnh sau đó (khỏi bệnh hay đỡ hay nặng lên hay tử vong) không được cập nhật và thống kê cho bệnh viện. Trong khi đó nếu người bệnh tử vong tại nhà, chính quyền chỉ thống kê theo khai báo của gia đình và lúc này nguyên nhân tử vong có thể không chính xác như chẩn đoán của bệnh viện. Do đó nếu có sự liên kết thông tin giữa các cơ sở y tế và địa phương hay nói cách khác nếu các thông tin của từng cá nhân trong cộng đồng được lưu trữ trên hệ thống thông tin quốc gia hoặc địa phương việc thống kê tử vong và nguyên nhân tử vong chắc chắn sẽ chính xác và dễ dàng hơn rất nhiều.

\section{Một số nguyên nhân chính gây tử vong:}

Nguyên nhân tử vong ở các đối tượng trong địa bàn nghiên cứu phản ánh mô hình tương tự như các nước đang phát triển trong giai đoạn chuyển đổi dịch tễ học. Một vài thập kỉ trước đây, các bệnh lây nhiễm đã là những nguyên nhân gây tử vong hàng đầu như bệnh lao, sốt rét và viêm phổi. Với những thành tựu của y tế công cộng, cũng như việc cải thiện của hệ thống y tế, giám sát bệnh dịch cùng với sự thành công của chương trình tiêm chủng, tử vong từ những bệnh này đã giảm một cách đáng kể. Tuy nhiên, Việt Nam lại phải đối mặt với những vấn đề sức khỏe khác. Các số liệu từ bệnh viện cho thấy các bệnh không lây nhiễm đang có xu hướng tăng lên trong những năm gần đây và hiện đang đứng đầu trong các nguyên nhân tử vong. ${ }^{10-12}$

Kết quả nghiên cứu cho thấy ba nguyên nhân gây tử vong hàng đầu lần lượt là viêm phổi $(16,3 \%)$, tai biến mạch máu não $(14,5 \%)$, tâm phế mạn $(6,6 \%)$. Kết quả của chúng tôi phù hợp với kết quả nghiên cứu về tình hình nguyên nhân tử vong ở Việt Nam được ghi nhận ở báo cáo các phương pháp và kết quả từ nhiều nguồn khác nhau. ${ }^{13-15}$

Kết quả cho thấy tử vong do các bệnh lý tim mạch đứng đầu là bệnh lý mạch máu não (14,5\%), tâm phế mạn (6,6\%), các bệnh lý mạch máu não và bệnh mạch vành cũng là nguyên nhân gây tử vong hàng đầu tại các nước khu vực Châu Âu và Tây Thái Bình Dương. ${ }^{16}$ Ở cả hai giới, tai biến mạch máu não đều đứng hàng đầu, không có sự khác biệt giữa nam và nữ. Tỷ lệ tử vong cao nhất ở nhóm người cao tuổi ( $\geq$ 60 tuổi), điều này có thể được giải thích do các yếu tố nguy cơ gồm bệnh nền tăng huyết áp, thói quen sử dụng rượu, thuốc lá, lối sống tĩnh tại ít hoạt động, đặc biệt là yếu tố tuổi tác. Điều này cho thấy cần sớm triển khai các chương 
trình can thiệp nhằm quản lí và theo dõi bệnh tăng huyết áp, phòng chống tác hại của thuốc lá giúp giảm thiểu tỷ lệ tử vong do các bệnh tim mạch đồng thời phải tích cực tuyên truyền cho người dân hiểu được sự nguy hiểm của nhóm bệnh tim mạch.

Tử vong do các bệnh hô hấp gồm: đứng đầu là viêm phổi chiếm 16,3\% nguyên nhân tử vong cả hai giới, nữ giới cao hơn nam giới (19,5\% so với $14,4 \%, p<0,01)$, sau đó là hen phế quản chiếm 2,1\%. Trong đó, tỷ lệ tử vong do viêm phổi chiếm tỷ lệ cao ở nhóm trẻ em dưới 5 tuổi và nhóm người cao tuổi ( $\geq 60$ tuổi). Điều này có thể giải thích do các nguy cơ về ô nhiễm không khí, khói bụi, môi trường độc hịa, tác hại của hút thuốc lá và hút thuốc thụ động. Bên cạnh đó việc cung cấp thiếu chất dinh dưỡng, trình độ văn hóa ít tiếp cận y tế và vac-xin cũng là nguy cơ gây tăng tỉ lệ tử vong do bệnh lý viêm phổi ở các nhóm tuổi này. Cần có những nghiên cứu sâu hơn về vấn đề này.

Tử vong do ung thư cũng là một trong những nguyên nhân tử vong hàng đầu. Tỷ lệ tử vong cao nhất ở nhóm tuổi từ 50 - 59 tuổi ở cả hai giới. Kết quả của nghiên cứu này cũng cho thấy trong số các trường hợp tử vong do ung thư, tỷ lệ tử vong do ung thư phổi ở cả hai giới là cao nhất, sau đó là ung thư gan. Điều này có thể được giải thích do thói quen lao động và sinh hoạt: làm việc nặng nhọc, môi trường độc hại, tác hại của hút thuốc lá chủ động và thụ động. Ung thư gan là nguyên nhân gây tử vong thường gặp trong các loại ung thư có thể là do thói quen uống rượu, tỷ lệ nhiễm vi rút viêm gan $\mathrm{B}$ ở Việt Nam khá cao. Bên cạnh đó người dân thường được chẩn đoán bị ung thư ở giai đoạn quá muộn vì vậy tỷ lệ tử vong cao.

Trong nghiên cứu này, kết quả đã chỉ ra rằng tai nạn thương tích là một trong mười nguyên nhân tử vong thường gặp. Các nhóm tuổi từ 5 - 14 tuổi và từ 15 - 49 tuổi, tử vong do tai nạn thương tích đều chiếm cao nhất. Trong các tai nạn thương tích, gặp nhiều nhất là tự tử, đứng đầu trong cả hai giới. Hiện nay, tự tử là một vấn đề đang nổi cộm của y tế công cộng Việt Nam và là nguyên nhân gây tử vong thường gặp nhất ở độ tuổi thanh niên và lứa tuổi lao động, tương tự như nhiều nước đang phát triển khác. ${ }^{13-15}$ Điều này gây ảnh hưởng lớn đến gia đình có người tử vong cũng như sự phát triển kinh tế của toàn xã hội. Kết quả này có thể được giải thích một phần cũng vẫn là do tính đặc thù của nhóm tuổi, đây là lứa tuổi đặc trưng bởi sự chuyển động, thay đổi và chuyển từ trạng thái này sang trạng thái khác, trong một số lĩnh vực cùng một lúc. Các yếu tố nguy cơ được trích dẫn nhiều nhất bao gồm rối loạn tâm thần, lạm dụng chất và mối quan hệ trong gia đình và xã hội. Hầu hết các nghiên cứu đồng ý rằng tự tử có liên quan chặt chẽ với các rối loạn tâm thần bao gồm trầm cảm nặng, rối loạn lưỡng cực, tâm thần phân liệt, rối loạn nhân cách. Thêm vào đó, đối tượng có yếu tố tâm thần thường kèm theo hành vi lạm dụng chất bao gồm nghiện rượu, sử dụng heroin và cocaine, ma túy ... Mặt khác, sự bốc đồng là đặc điểm nhân cách ở lứa tuổi này cũng là nguy cơ khác đối với tự tử của thanh thiếu niên do họ khó khăn trong việc quản lý các cảm xúc khác nhau, nghèo kỹ năng giải quyết vấn đề hơn so với các đồng nghiệp của họ. Họ thường xuyên phải đối mặt với những kì vọng cao, đôi khi quá cao, từ những người thân hoặc đồng nghiệp. Theo đó, để giảm các yếu tố bất lợi và tăng cường các yếu tố bảo vệ càng nhiều càng tốt bằng cách cung cấp các kiến thức về sức khỏe tâm thần ví dụ đưa kiến thức vào chương trình giáo dục trong các trường học, cung cấp đường dây nóng về các vấn đề khủng hoảng và trực tuyến giúp đỡ, phát hiện và tương tác với cá nhân hoặc gia đình có thành viên được xác định có ý định tự tử. ${ }^{17}$ 
Trong khi đó, đuối nước là nguyên nhân thường gặp xếp thứ 2 trong nhóm nguyên nhân tai nạn thương tích, thường gặp ở nhóm tuổi từ $1-5$ tuổi và từ 5 - 14 tuổi. Kết quả này cũng phù hợp với một nghiên cứu theo dõi về tử vong do tai nạn thương tích ở trẻ em: đuối nước cũng là nguyên nhân hàng đầu gây tử vong, đặc biệt ở lứa tuổi từ 0 đến $14 .{ }^{16}$ Đối với nhóm trẻ 1 - 5 tuổi, điều này có thể giải thích do hậu quả của việc đứa trẻ bị bỏ lại một mình hoặc người chăm sóc không giám sát cẩn thận (ví dụ anh chị em để trẻ trong hoặc gần nước), thêm vào đó trình độ học vấn của gia đình cũng là yếu tố liên quan tới tỉ lệ đuối nước cao ở trẻ. Đối với nhóm tuổi từ 5 - 14 tuổi, có thể giải thích do đặc tính thích khám phá, thói quen tắm ao hồ, sông suối của các em. Điều này cho thấy sự cần thiết trong việc giáo dục nâng cao ý thức về mức độ nguy hiểm của việc cho trẻ em chơ ở ao hồ khi không có người lớn giám sát, cũng như thể hiện sự cần thiết trong việc tiến hành việc tổ chức dạy bơi cho trẻ em vào trong chương trình dạy học ở các trường tiểu học và trung học cơ sở trên toàn quốc. Ở nhóm tuổi từ 15-49 tuổi thì tai nạn giao thông là nguyên nhân thường gặp, đây chính là nhóm tuổi thanh niên và lứa tuổi lao động, tương tự như nhiều nước đang phát triển khác. ${ }^{18}$ Kết quả này có thể được giải thích do đây là lứa tuổi hoạt động kinh tế chủ yếu nên thường xuyên phải tham gia giao thông, thêm vào đó Việt Nam đang có những bước tiến lớn trong phát triển kinh tế, quá trình đô thị hóa đang diễn ra nhanh chóng do vậy số lượng và số loại phương tiện tham gia giao thông tăng một cách nhanh chóng, đặc biệt là xe máy, nhưng đường xá giao thông lại không đáp ứng được với sự gia tăng của này. Mặt khác ý thức tham gia giao thông của người dân còn kém đặc biệt là ở độ tuổi vị thành niên và thanh niên cũng đã góp phần làm tỷ lệ tử vong do tai giao thông tăng lên. Kết quả này cũng cho thấy tai nạn giao thông chưa hề giảm mặc dù đã có rất nhiều hoạt động tuyên truyền, cảnh báo cho những người tham gia giao thông.

Số trường hợp tử vong do các bệnh lây nhiễm vẫn còn cao, xếp thứ sáu trong mười nguyên nhân thường gặp, trong đó đứng đầu là HIV/ AIDS. Cũng trong nghiên cứu này, số trường hợp tử vong do HIVIAIDS ở nam cao hơn nhiều so với nữ $(3,6 \%$ so với $1,6 \%, p<0,01)$. Tỉ lệ tử vong do HIVIAIDS cao ở nam giới là do nam giới thường có các hành vi có nguy cơ cao như nghiện chích ma túy, cuộc sống buông thả hơn nữ giới. Đặc biệt HIVIAIDS là nguyên nhân tử vong hàng đầu ở nhóm tuổi 15 - 49, đây là vấn đề đáng quan tâm tại Điện Biên khi đây là lứa tuổi sinh đẻ của phụ nữ và cũng là độ tuổi lao động của cả 2 giới. Do đó đòi hỏi phải có sự quan tâm đúng mức của ngành y tế cũng như của cả cộng đồng.

Kết quả của điều tra này phản ánh mô hình tương tự ở các nước đang phát triển trong giai đoạn chuyển đổi dịch tễ học. Với sự già hóa dân số, hiệu quả phòng và điều trị các bệnh lây nhiễm được cải thiện, lối sống thay đổi đã là những yếu tố góp phần vào giảm gánh nặng của những bệnh lây nhiễm, nhưng lại làm tăng gánh nặng của các bệnh không lây nhiễm. Các số liệu thống kê từ hệ thống các bệnh viện của Việt Nam cũng cho thấy các bệnh không lây nhiễm đang có xu hướng tăng lên trong những năm gần đây và hiện đang đứng hàng đầu trong các nguyên nhân gây tử vong.

Hạn chế của nghiên cứu là số liệu sử dụng từ năm 2017, có thể mô hình tử vong của địa phương đã thay đổi. Bên cạnh đó số liệu chỉ của tỉnh Điện Biên do đo chỉ đại diện cho tỉnh và không có tính đại diện cho vùng hay khu vực.

\section{KẾT LUẬN}

Ba nguyên nhân gây tử vong gặp nhiều nhất tại Điện Biên năm 2017 là viêm phổi (16,3\%), tai biến mạch máu não $(14,5 \%)$, tâm phế mạn 
(6,6\%). Các nguyên nhân tử vong do nhóm bệnh lý tim mạch chiếm cao nhất, thường gặp là tai biến mạch máu não (14,5\%), tiếp theo là tâm phế mạn $(6,6 \%)$. Các nguyên nhân về hô hấp là nhóm nguyên nhân gây tử vong thứ 2 , đứng đầu là bệnh viêm phổi (16,3\%). Các nguyên nhân về ung thư là nhóm nguyên nhân gây tử vong đứng hàng thứ 3 , trong đó hay gặp nhất là ung thư phổi và ung thư gan. Tai nạn thương tích là một trong những nguyên nhân hàng đầu, đặc biệt là tự tử, đuối nước, tai nạn giao thông.

\section{TÀI LIẸU THAM KHẢO}

1. WHO. WHO | Counting the dead is essential for health. WHO. Published 2006. Accessed January 31, 2021. https://www.who. int/bulletin/volumes/84/3/interview0306/en/

2. WHO. Civil registration: why counting births and deaths is important. Published 2014. Accessed January 31, 2021. https://www.who.int/ news-room/fact-sheets/detail/civil-registrationwhy-counting-births-and-deaths-is-important.

3. Subbaraman N. Why daily death tolls have become unusually important in understanding the coronavirus pandemic. Nature. Published online April 9, 2020. doi:10.1038/d41586-02001008-1.

4. UNDP. Counting What Counts in Development | Human Development Reports. Accessed January 31, 2021. http://hdr.undp.org/ en/content/counting-what-counts-development.

5. Rasika Rampatige a, Lene Mikkelsen b, Bernardo Hernandez c, lan Riley a \& Alan D Lopez. WHO|Hospital cause-of-death statistics: what should we make of them? WHO. Published 2014. Accessed January 31, 2021. https://www. who.int/bulletin/volumes/92/1/13-134106/en/

6. Organization WH. Strengthening Civil Registration and Vital Statistics for Births, Deaths and Causes of Death: Resource Kit. World Health Organization; 2013. Accessed
January 31, 2021. https://apps.who.int/iris/ handle/10665/78917.

7. Huong DL, Van Minh $\mathrm{H}$, Janlert U, Van $D D$, Byass P. Socio-economic status inequality and major causes of death in adults: a 5-year follow-up study in rural Vietnam. Public Health. 2006;120(6):497-504. doi:10.1016/j. puhe.2006.03.003.

8. Hoa NP, Rao C, Hoy DG, Hinh ND, Chuc NTK, Ngo DA. Mortality measures from sample-based surveillance: evidence of the epidemiological transition in Viet Nam. Bull World Health Organ. 2012;90(10):764-772. doi:10.2471/BLT.11.100750.

9. Bộ Y tế. Thông tư 27/2014/TT-BYT Hệ thống biểu mẫu thống kê y tế cơ sở y tế tuyến tỉnh huyện xã. Published 2014. Accessed January 31, 2021. https://thuvienphapluat.vn/van-ban/ Bo-may-hanh-chinh/Thong-tu-27-2014-TTBYT-He-thong-bieu-mau-thong-ke-y-te-co-so-yte-tuyen-tinh-huyen-xa-253463.aspx.

10. Bộ $\mathrm{Y}$ tế $\mathrm{N}$ đối tác $\mathrm{y}$ tế. Báo Cáo Tổng Quan Ngành y Tế 2017.; 2018.

11. Bộ $\mathrm{Y}$ tế $\mathrm{N}$ đối tác y tế. Báo Cáo Tổng Quan Ngành y Tế Năm 2015.; 2016.

12. Bộ $\mathrm{Y}$ tế $\mathrm{N}$ đối tác $\mathrm{y}$ tế. Báo Cáo Tổng Quan Ngành y Tế Năm 2016.; 2017.

13. IHME. Vietnam. Institute for Health Metrics and Evaluation. Published September 9, 2015. Accessed January 31, 2021. http:// www.healthdata.org/vietnam.

14. US CDC. Vietnam I CDC Global Health. Published January 28, 2021. Accessed January 31, 2021. https://www.cdc.gov/globalhealth/ countries/vietnam/default.htm.

15. Statista. Vietnam: number of deaths by cause 2017. Statista. Published 2019. Accessed January 31, 2021. https://www.statista.com/ statistics/1107639/vietnam-number-of-deathsby-cause/ 
16. WHO. The top 10 causes of death. Published 2020. Accessed January 31, 2021. https://www.who.int/news-room/fact-sheets/ detail/the-top-10-causes-of-death.

17. Mental Health Issues On the Rise Among Adolescents, Young Adults. AJMC. Accessed July 17, 2021. https://www.ajmc.com/ view/mental-health-issues-on-the-rise-among- adolescents-young-adults.

18. WHO. Global Health Estimates: Life expectancy and leading causes of death and disability. Published 2020. Accessed January 31, 2021. https://www.who.int/data/ maternal-newborn-child-adolescent/gama/ activities-of-gama.

\section{Summary \\ CAUSES OF MORTALITY OBSERVED BY AGE GROUPS IN DIEN BIEN, 2017}

Understanding causes of death for different age groups of the population is important in guiding research as well as planning and directing health activities at the local and national level. In 2017, in Dien Bien province, Vietnam, the causes of death differed by age groups: For children aged 1 to under 5 years, the leading cause of death was pneumonia (41.3\%); for children aged 5 - 14 years, drowning is the leading cause of death (22.2\%); for those in the $15-49$ age group, the leading cause of death was HIVIAIDS (9.6\%); for those in the 50-59 age group, the leading cause of death was cerebrovascular accident (19.8\%); For those older than 59 years old, the leading cause of death in the elderly was also cerebrovascular accident $(23.9 \%)$. Notably, $77.9 \%$ of the deaths in our study occurred at home. This is a challenge that confound mortality and cause of death statistics since many sick people may return home when there is no hope of survival or no economic ability to pursue treatment.

Keywords: causes of mortality, diferent ages, causes, Dien Bien, Viet Nam. 